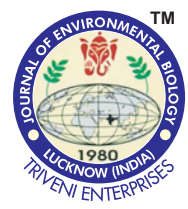

\title{
Application of grey relational analysis for the optimization of process parameters in adsorption process
}

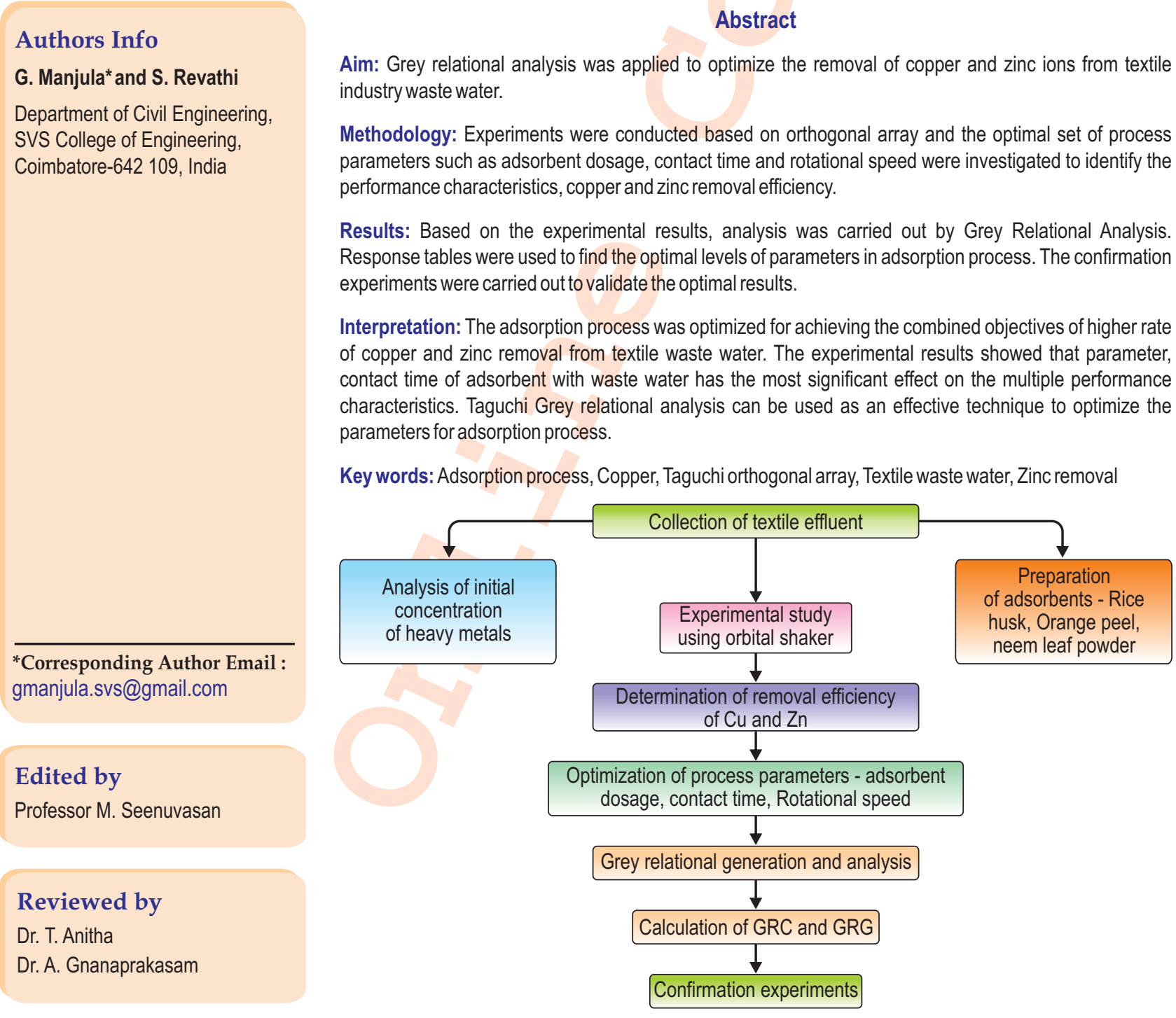

How to cite : Manjula, G. and S. Revathi: Application of grey relational analysis for the optimization of process parameters in adsorption process. J. Environ. Biol., 40, 763-768 (2019). DOI : http://doi.org/10.22438/jeb/40/4(SI)/JEB_17 


\section{Introduction}

Over the past few decades rapid industrialization has contributed to high economic growth. However it has also lead to severe environmental pollution. Heavy metals that are released into the environment pose a significant threat to the environment and public health because of their toxicity and bioaccumulation in the food chain (Bahadir et al., 2007). Heavy metals like lead, mercury, copper, cadmium, zinc, nickel and chromium are among the most common pollutants found in industrial effluents which cause serious threat to environment, animals and humans because of their extreme toxicity (Liu et al., 2006). A number of technologies have been developed over the years to remove heavy metals from industrial wastewater. The most important technologies for heavy metal removal include adsorption and flocculation (Abdel et al., 1996; Amuda et al., 2006). The key benefit of adsorption method for heavy metal removal is less initial cost as well as operation cost and unproblematic design (Acar and Eren, 2006).

The major industries have required advanced treatment facilities for treating their industrial effluents. However, the small scale industries do not have such costly pollution control equipments or facilities to treat its effluent. The toxic metals cause physical discomfort and sometimes life threatening illness and irreversible damage to vital body systems (Malik, 2004). Some studies indicate that moderate lead poisoning can result in neurobehavioral and intelligence deficits (Selatnia et al., 2004). The removal and recovery of heavy metals is important from the point of resource recovery also (Puranik et al., 1999). It is therefore regulated by many countries that heavy metal ions must be treated to certain levels before they are discharges into watercourses (Chen et al., 2007). The present day scenario of tremendous industrial pollution has prompted this experimental investigation for a systematic and detailed study of adsorption of toxic heavy metals in water samples collected from a textile industry in Tiruppur located in the state of Tamilnadu, India. Tiruppur is considered as one of the fastest developing industrial zone in the state. Use of agricultural byproducts as adsorbents for heavy metal removal from industrial waste water has been studied extensively. Rice husk is found to be an effective adsorbent for the removal of arsenic from groundwater (Amin 2006). 'Rice polish' (an agricultural residue) was utilized successfully for the removal of arsenic from aqueous solution (Ranjan, 2009). A novel orange peel adsorbent developed from an agricultural waste material was characterised and utilised for the removal of Remazol Brilliant Blue from an artificial textile-dye effluent (Mafra et al., 2013). Most of the studies have focused on organic wastes such as rice husk and neem bark (El-Said et al., 2012; Bhattacharya et al., 2006). Black gram husk (Saeed and Iqbal 2003), Waste tea, Walnut shell has also been used effectively (Orhan and Büyükgüngör et al., 1993). Experimental studies on adsorbents like maize leaf (Babarinde et al., 2006), teak leaf powder (King et al., 2006), Coraindrum sativum
(Karunasagar et al., 2005), lalang (Imperata cylindrica) leaf powder (Hanafiah et al., 2007), peanut hull pellets (Johnson et al., 2002), saltbush (Atriplex canescens) leaves (Sawalha et al., 2007), tree fern (Ho and Wang, 2004; Ho et al., 2004; Ho, 2003), grape stalk wastes (Villaescusa et al., 2004), etc. have also proved to be successful for removal of heavy metals.

Statistical design of experiments is a useful technique for obtaining valuable and statistically significant models of phenomenon by performing minimum number of experiments. An experimental design methodology should be applied such that complex information are processed easily resulting in significant reduction of experimental time (Kincl et al., 2005). The most common techniques used for optimization are Taguchi method and Response Surface Methodology. Response Surface Methodology is a statistical method based on the multivariate non-linear model that has been widely used for optimization of process variables of adsorption (Zulkali et al., 2006; Goel et al., 2006). Taguchi methods have proved to be a useful approach for improving product quality at a relatively low cost (Tzeng and Chen, 2006). The results of several investigations have revealed that process parameters such as initial concentration, speed, dosage, $\mathrm{pH}$ and adsorbent type significantly affect adsorption process (Cojocaru and Zakrzewska-Trznadel 2007; Wachter and Cordery 1999; Egirani et al., 2005; Goyal et al., 2001; Ajmal et al., 1198; Ravikumar et al., 2005).

The classical optimization technique of changing one parameter at a time to study the effect of parameters on the response is time consuming and expensive. Taguchi Method is generally used to analyze optimal process parameters of a single quality characteristic. This method focus on optimizing a single quality response (Lin, 2004). However, products in some processes have more than one quality response which should be considered. Taguchi method is used to decide optimal factor levels for multi-responses which may increase uncertainty during the decision-making process (Balasubramanian and Ganapathy, 2011). This problem can be solved by the grey system theory introduced by Deng (1989). It proposes integration of Grey relational analysis and Taguchi Method to resolve multiple quality characteristics. This method transforms multiple quality characteristics into single grey relational grades. By comparing the computed grey relational grades, the arrays of respective quality characteristics are obtained in accordance with response grades to select an optimal set of process parameters. In this study, different process parameters of adsorption process such as speed of rotation, dosage of coagulant and contact time were optimized to achieve the best multiple quality characteristics using the Grey Relational method.

\section{Materials and Methods}

Experimental setup: The samples were collected from textile industry effluent, located in Tiruppur district of Tamilnadu state in 
Table 1: Process parameters and their limits

\begin{tabular}{llll}
\hline Parameter & Level 1 & Level 2 & Level 3 \\
\hline Adsorbent & Rice husk & Orange peel & Neem leaf \\
Dosage $\left(\mathrm{mg} \mathrm{l}^{-1}\right)$ & 2 & 4 & 6 \\
Speed $(\mathrm{rpm})$ & 100 & 150 & 200 \\
Time $(\mathrm{min})$ & 30 & 60 & 90 \\
\hline
\end{tabular}

Table 2: Orthogonal array of the Experimental Runs

\begin{tabular}{lllll}
\hline Run No. & \multicolumn{3}{c}{ Levels of Parameters } \\
\cline { 2 - 5 } & Adsorbent & Dosage $\left(\mathrm{mgl} \mathrm{l}^{-1}\right)$ & Speed $(\mathbf{r p m})$ & Time $(\mathbf{m i n})$ \\
\hline 1. & Rice husk & 6 & 200 & 90 \\
2. & Rice husk & 2 & 100 & 30 \\
3. & Orange peel & 6 & 150 & 30 \\
4. & Rice husk & 4 & 150 & 60 \\
5. & Orange peel & 2 & 200 & 60 \\
6. & Neem leaf & 2 & 150 & 90 \\
7. & Neemleaf & 4 & 200 & 30 \\
8. & Neem leaf & 6 & 100 & 60 \\
9. & Orange peel & 4 & 100 & 90 \\
\hline
\end{tabular}

India. The initial concentration of heavy metals (chromium, copper and zinc) present in waste water sample was tested using AA301 Atomic Adsorption Spectrophotometer. Sampling procedure was done as per code IS 3025 part-1. From the initial test results it was found that chromium $(\mathrm{VI})$ ions are present within permissible limit in the waste water samples. Copper (II) and Zinc (II) ions were present in initial concentrations of $41.3 \mathrm{ppm}$ and $36.1 \mathrm{ppm}$ respectively. The adsorption process was carried out as batch process using orbital shaker. Dried rice husk, orange peel and neem leaf powder were used as adsorbents. After the experiments, the samples were filtered through quantitative filter papers and the samples were tested for heavy metals (Copper and Zinc) using AA301 Atomic adsorption spectrophotometer.

Design of experiments : Special design of orthogonal arrays was used to study the entire parameter space in Taguchi method with a limited number of experiments (Lin, 2004). The experiments were carried out by using the standardized Taguchi based experimental design, L9 orthogonal array with three levels (coded by: 1, 2 and 3) of four main parameters, namely, adsorbent material, dosage of adsorbent, rotational speed and contact time as shown in Table 1.

Grey relational generation: The Grey relational analysis for optimization of process parameters was proposed by Deng (1989). It was used for measuring the degree of relationship between sequences by Grey relational grade. Tzeng and Chen (2006) used grey relational analysis to optimize the process parameters in turning of tool steels. By employing Grey relational analysis associated with the Taguchi method, optimization of complicated multi-response characteristics can be converted into optimization of a single response characteristic with Grey relational grade as an objective function. In the present study, the objectives were to maximize the removal efficiency of copper and zinc in adsorption process. Hence, removal efficiency of copper and removal efficiency of zinc as multi-responses were combined by Grey relational grade using Grey relational analysis.

In Grey relational analysis, the first step was to perform the Grey relational generation in which the results of the experiments were normalized in the range between 0 and 1 , due to different measurement units. Data pre-processing converts the original sequences to a set of comparable sequences. Normalizing the experimental data for each quality, characteristic was done according to the type of performance response. Thus, the normalized data processing for maximizing the removal efficiency corresponding to larger-the-better criterion can be expressed as:

$$
x_{i}(k)=\left[y_{i}(k)-\min \cdot y_{i}(k)\right] /\left[\max \cdot y_{i}(k)-\min \cdot y_{i}(k)\right]
$$

where, $i=1,2,3, \ldots, m$, $m$ is the number of experimental runs in Taguchi orthogonal array. In the present $L 9$ orthogonal array was selected $(m=9) . k=1,2, \ldots, n, \mathrm{n}$ is the number of quality characteristics or process responses, In the present study removal efficiency of copper and zinc are selected $(n=2)$; Min. $y_{i}$ $(k)$ is the smallest value of $y_{i}(k)$ for the $k^{\text {th }}$ response; Max. $y_{i}(k)$ is the largest value of $y_{i}(k)$ for $k^{\text {th }}$ response; $x_{i}(k)$ is the value after Grey relational generation.

The normalized values of copper and zinc removal efficiency are shown in Table 3. 
Table 3: Normalized values and deviation sequences ( $\eta$-Removal efficiency)

\begin{tabular}{|c|c|c|c|c|}
\hline \multirow[t]{2}{*}{ Runno. } & \multicolumn{2}{|c|}{ Normalized values for response } & \multicolumn{2}{|c|}{ Deviation Sequences $\Delta_{\mathrm{oi}}(\mathbf{k})$} \\
\hline & $\mathrm{Cu} \eta$ & $\mathrm{Zn} \eta$ & Cu $\eta$ & $\mathrm{Zn} \eta$ \\
\hline 1 & 0.44 & 0.13 & 0.56 & 0.87 \\
\hline 2 & 0.75 & 0.00 & 0.25 & 1.00 \\
\hline 3 & 1.00 & 0.79 & 0.00 & 0.21 \\
\hline 4 & 0.46 & 0.96 & 0.54 & 0.04 \\
\hline 5 & 0.86 & 0.51 & 0.14 & 0.49 \\
\hline 6 & 0.00 & 0.37 & 1.00 & 0.63 \\
\hline 7 & 0.28 & 0.69 & 0.72 & 0.31 \\
\hline 8 & 0.44 & 0.82 & 0.56 & 0.18 \\
\hline 9 & 0.47 & 0.93 & 0.53 & 0.07 \\
\hline
\end{tabular}

Table 4: Calculated GRC \& GRG

\begin{tabular}{lllll}
\hline Run no. & \multicolumn{2}{c}{ GRC } & GRG & RANK \\
\cline { 2 - 3 } & Copper removal $\eta$ & Zinc removal $\eta$ & \\
\hline 1. & 0.4705 & 0.3945 & 0.4325 & 8 \\
2. & 0.6673 & 0.36 & 0.5137 & 7 \\
3. & 0.9998 & 0.7596 & 0.8797 & 1 \\
4. & 0.4821 & 1.0041 & 0.7422 & 2 \\
5. & 0.7809 & 0.5466 & 0.6638 & 4 \\
6. & 0.3333 & 0.4794 & 0.4064 & 9 \\
7. & 0.4109 & 0.6627 & 0.5368 & 5 \\
8. & 0.4707 & 0.7985 & 0.6346 & 3 \\
9. & 0.4851 & 0.9434 & 0.7143 & 3 \\
\hline
\end{tabular}

Grey relational coefficient and Grey relational grade: The second step is to calculate the Grey relational coefficient based on the normalized experimental data to represent the correlation between the desired and actual experimental data. The average of Grey relational coefficient corresponding to each performance characteristic was calculated to determine overall grey relational grade. The optimal combination of process parameters was evaluated considering the highest Grey relational grade by using the Taguchi method. Based on the normalized experimental data, the Grey relation coefficient can be calculated using the following equation:

$$
\varepsilon_{\mathrm{i}}(\mathrm{k})=\left(\Delta_{\min }+\varepsilon \Delta_{\max }\right) /\left(\Delta_{\mathrm{oi}}(\mathrm{k})+\varepsilon \Delta_{\max }\right)
$$

Where, $\Delta_{o i}=\left\|x_{0}(k)-x_{i}(k)\right\|$ is difference of absolute value between $x_{0}(k)$ and $x_{i}(k), x_{0}(k)$ is the reference sequence of $k^{\text {th }}$ quality characteristics. $\Delta_{\min }$ and $\Delta_{\max }$ are respectively the minimum and maximum values of absolute differences $\left(\Delta_{\mathrm{oi}}\right)$ of all comparing sequences. $\varepsilon$ is a distinguishing coefficient, $0 \leq \varepsilon \leq 1$, the purpose of which was to weaken the effect of $\Delta_{\max }$ when it gets too big, and thus enlarges the difference significance of relational coefficient. If all parameters are given equal preference, $\varepsilon$ is taken as 0.5 .

The Grey relation coefficient of each performance characteristic is shown in Table 4. After averaging the Grey relational coefficients, the Grey relational grade Yi can be calculated as follows:

$$
\mathrm{y}_{\mathrm{i}}=\frac{1}{\mathrm{n}} \sum_{\mathrm{k}=1}^{\mathrm{n}} \varepsilon_{\mathrm{i}}=(\mathrm{k})
$$

where, $i=1,2,3 \ldots 9$, (L9 orthogonal array is selected), $\varepsilon_{\mathrm{i}}=(\mathrm{k})$ is the Grey relational coefficient of $k^{\text {th }}$ response in $i^{\text {th }}$ experiment and $\mathrm{n}$ is the number of responses.

\section{Results and Discussion}

The optimum level of process parameters is the level with highest Grey relational grade. The higher value of Grey relational grade indicates an intense relational degree between the reference sequence $x_{0}(k)$ and the given sequence $x_{i}(k)$. The Grey relational coefficients (GRC) and Grey relational grade (GRG) are presented in Table 4. The highest GRG of 0.8797 was obtained for experiment number 3 and it was ranked 1 among other Grey relational grades. Therefore, the experiment number 3 was the best combination of adsorption process for removal of copper (II) and zinc (II) among the nine experiments.

Grey relational analysis is used to convert the multiobjective optimization problem into a single equivalent objective 
Table 5: Response table for GRG

\begin{tabular}{lllllll}
\hline \multirow{2}{*}{ Symbol } & Parameters & \multicolumn{3}{c}{ GRG } & \multirow{2}{*}{ Main effect } & Rank \\
\cline { 3 - 5 } & & Level1 & Level2 & Level 3 & & \\
\hline A & Adsorbent & 0.5628 & 0.6383 & $0.6402^{*}$ & 0.0774 & 4 \\
B & Dosage & 0.5279 & $0.6644^{*}$ & 0.6489 & 0.1365 & 2 \\
C & Time & 0.6434 & $0.6802^{*}$ & 0.5177 & 0.1625 & 1 \\
D & Speed & 0.6207 & $0.6761^{*}$ & 0.5449 & 0.1312 & 3 \\
\hline
\end{tabular}

Total mean value of $G R G\left(\tilde{a}_{m}\right)=0.8183$; Levels for optimum GRG

Table 6: Improvement in GRG with optimized control parameters

\begin{tabular}{lll}
\hline & \multicolumn{2}{c}{ Optimal control parameters } \\
\cline { 2 - 3 } & Taguchi orthogonal array & Grey theory prediction design \\
\hline Levels & $\mathrm{C}_{2} \mathrm{~B}_{3} \mathrm{D}_{1} \mathrm{~A}_{2}$ & $\mathrm{C}_{2} \mathrm{~B}_{2} \mathrm{D}_{2} \mathrm{~A}_{3}$ \\
GRG & 0.1332 & 0.206 \\
\hline
\end{tabular}

Improvement in GRG $=0.0728$

function. The highest Grey relational grade is considered for evaluating optimal combination of process parameters using the Taguchi method (Balasubramanian and Ganapathy, 2011). The mean values of Grey relational grade for each level of process parameters are calculated and summarized in Table 5. The larger the Grey relational grade, the better the multiple quality characteristics (Hasani et al, 2012). Therefore, the optimal parameter for better copper and zinc removal efficiency is $\left(A_{3} B_{2} C_{2} D_{2}\right)$.

Confirmation experiment : The improvement of performance characteristics in adsorption process parameters was verified using confirmation test. Optimal parameters were selected for the confirmation test (Table 6). Estimated GRG $\gamma_{i}$ using optimal level of process parameters was calculated by using Equation

$$
\gamma=\gamma_{\mathrm{m}}+\sum_{\mathrm{i}=1}^{\mathrm{q}}\left(\gamma_{\mathrm{i}}-\gamma_{\mathrm{m}}\right)
$$

Where, $\gamma_{m}$ is the total mean of GRG, $\gamma_{i}$ is the mean of GRG at optimal level, and $q$ is the number of parameters that significantly affect multiple-performance characteristics.

The $C_{2} B_{2} D_{2} A_{3}$ was an optimal combination of parameters by Grey relational analysis. Therefore, the $C_{2} B_{2} D_{2} A_{3}$ optimal combination of parameters was regarded as the confirmation test.

Table 6 shows the comparison of experimental results by using the initial $\left(\mathrm{OA}, \mathrm{C}_{2} \mathrm{~B}_{3} \mathrm{D}_{1} \mathrm{~A}_{2}\right)$ and optimal (grey theory prediction design $\mathrm{C}_{2} \mathrm{~B}_{2} \mathrm{D}_{2} \mathrm{~A}_{3}$ ) process parameters. In conclusion, it is clearly shown that the multiple performance characteristics in adsorption process were significantly improved by increase in Grey relational grade of 0.0728 .

The process parameters with multiple performance characteristics of copper and zinc removal efficiency was optimized using grey relational grade obtained from grey relational analysis. The experimental results indicate that contact time has the most significant effect on the multiple performance characteristics followed by coagulant dosage whereas rotational speed of orbital shaker has the least significant effect on the performance characteristics. The obtained results showed that dried orange peel powder is good adsorbing medium for copper and zinc ion present in textile wastewater. The level of three variable, dosage of coagulant orange peel , $6 \mathrm{mg} \mathrm{I}^{-1}$; speed of rotation, $150 \mathrm{rpm}$; contact time, 30 min, were found to be optimum for maximum copper and zinc ion removal efficiency. The result of confirmation tests yielded an improvement of 0.0728 in grey relational grade, after validation. Integration of grey relational analysis and Taguchi method can be effectively applied for the optimization of process parameters and help to improve process efficiency.

\section{References}

Abdel-shafy, H., W. Hegemann and C. Guldner: Fate of heavy metals via chemical-biological upgrading of sewage sludge treatment plant. Environ. Manage. Hlth., 713, 28-36 (1996).

Acar, F.N. and Z. Eren: Removal of CU (II) ions by activated poplar sawdust (Samsun Clone) from aqueous solutions. J. Hazard . Mater. B., 137, 909-914 (2006).

Ajmal, M., A.H. Khan, S. Ahmad and A. Ahmad: Role of sawdust in the removal of Cu (II) from industrial waste. Water Res., 32, 3085-3091 (1998). 
Amin, M.N.: Removal of arsenic in aqueous solutions by adsorption onto waste rice husk. Ind. Eng. Chem. Res., 45, 8105-8110 (2006).

Amuda, O.S., I.A. Amoo and O.O. Ajayi: Coagulation flocculation process in the treatment of beverage industrial wastewater. J. Hazard. Mater. B., 129, 69-72 (2006).

Babarinde, N.A.A., J.O. Babalola and R.A. Sanni: Biosorption of lead ions from aqueous solution by maize leaf. Int. J. Phys. Sci., 1, 2326 (2006).

Bahadir, T., G. Bakan, L. Aitas and H. Buyukgungor: The investigation of lead removal by biosorption: An application at storage battery industry wastewaters. Enzyme Microb. Technol., 41, 98-102 (2007).

Balasubramanian, S. and S. Ganapathy: Grey Relational Analysis to determine optimum process parameters for Wire Electro Discharge Machining (WEDM). Int. J. Eng. Sci. Echnol., 3, 95-101 (2011).

Bhattacharya, A.K., S.N. Mandal and S.K. Das: Adsorption of Zn (II) from aqueous solution by using different adsorbents. Chem. Eng. J., 123, 43-51 (2006).

Chen, J., L. Wang and S. Zou: Determination of lead biosorption properties by experimental and modeling simulation study. Chem. Eng. J., 131, 209-215(2007).

Cojocaru, C. and G.Z. Trznadel: Response surface modeling and optimization of copper removal from aqua solutions using polymer assisted ultrafiltration. J. Membr. Sci., 298, 56-70 (2007).

Deng, J.: Introduction to grey System. J. Grey Syst., 1, 1-24 (1989).

Egirani, D.E., A.R. Baker and J.E. Andrews: Copper and zinc removal from aqueous solution, by mixed mineral systems, I. Reactivity and removal kinetics. J. Colloid Interface Sci., 291, 319-325 (2005).

El-Said, A.G., N.A. Badawy and S.E. Garamon: Adsorption of Cadmium (II) and Mercury (II) onto natural adsorbent rice husk ash (RHA) from aqueous solutions: study in single and binary system. Int. J. Chem., 2012, 58-68 (2012).

Goel, J., K. Kadirvelu, C. Rajagopal and V.K. Garg: Cadmium (II) uptake from aqueous solution by adsorption onto carbon aerogel using a response surface methodological approach. Ind. Eng. Chem. Res., 45, 6531-6537(2006).

Goyal, M., V.K. Rattan, D. Aggarwal and R.C. Bansal: Removal of copper from aqueous solutions by adsorption on activated carbons. Colloids Surf. A, 190-229 (2001).

Hanafiah, M.A.K., W.S.W. Ngah, H. Zakaria and S.C. Ibrahim: Batch study of liquid-phase adsorption of lead ions using Lalang (Imperata cylindrica) leaf powder. J. Biol. Sci., 7, 222-230 (2007).

Ho, Y.S., W.T. Chiu, C.S. Hsu and C.T. Huang: Sorption of lead ions from aqueous solution using tree fern as a sorbent. Hydrometallurgy, 73, 55-61 (2004).

Ho, Y.S. and C.C. Wang: Pseudo-isotherms for the sorption of cadmium ion onto tree fern. Process Biochem., 39, 759-763 (2004).

Ho, Y.S.: Removal of copper ions from aqueous solution by tree fern. Water Res., 37, 2323-2330 (2003).

Hasani, H., S. A. Tabatabaei and G. Amiri: Grey Relational Analysis to Determine the Optimum Process Parameters for Open-End Spinning Yarns. J. Eng. FiberFabr., 7, 81-86 (2012).

Johnson, P.D., M.A. Watson, J. Brown and I.A. Jefcoat: Peanut hull pellets as a single use sorbent for the capture of $\mathrm{Cu}$ (II) from wastewater. Waste Manage., 22, 471-480 (2002).

Karunasagar, D., M.V.B. Krishna, S.V. Rao and J. Arunachalam: Removal of preconcentration of inorganic and methyl mercury from aqueous media using a sorbent prepared from the plant
Coriandrum sativum. J. Hazard .Mater. B., 118, 133-139 (2005).

Kincl, M., S. Turk and F. Vrecer: Application of experimental design methodology in development and optimization of drug release method. Int. J. Pharm., 291, 39 (2005).

King, P., P. Srivinas, Y.P. Kumar and V.S.R.K. Prasad: Sorption of copper (II) ion from aqueous solution by Tectona grandis I.f. (teak leaves powder). J. Hazard. Mater . B., 136, 560-566 (2006).

Lin, C.L.: Use of the taguchi method and grey relational analysis to optimize turning operations with multiple performance characteristics. Mat. Manuf. Proces., 19, 209-220 (2004).

Liu, Y.G., T. Fan, G. Zeng, X. Li, Q. Tong, F. Ye, M. Zhou, W. Xu and Y. Huang: Removal of cadmium and zinc ions from aqueous solution by living Aspergillus niger. Trans. Nonferr. Met. Soc. China, 16, 681-686 (2006).

Mafra, M.R., L.I. Mafra, D.R. Zuim, E.C. Vasques and M.A. Ferreira: Adsorption of remazol brilliant blue on an orange peel adsorbent. Braz. J. Chem. Eng., 7,657-665 (2013).

Malik, A.: Metal bioremediation through growing cells. Environ. Int., 30, 261-278(2004).

Orhan, Y. and H. Büyükgüngör: The removal of heavy metals by using agricultural wastes. Water Sci. Technol., 28, 247-255 (1993).

Puranik, P., J. Modak and K. Paknikar: A comparative study of the mass transfer kinetics of metal biosorption by microbial biomass. Hydrometallurgy, 52, 189-197(1999).

Ranjan, D.: Biosorption of arsenic from aqueous solution using agricultural residue rice polish. J. Hazard. Mater., 166, 1050-1059 (2009).

Ravikumar, K., K. Pakshirajan, T. Swaminathan and K. Balu: Optimization of batch process parameters using response surface methodology for dye removal by a novel adsorbent. Chem. Eng. J., 105, 131-138 (2005).

Saeed, A. and M. Iqbal: Bioremoval of cadmium from aqueous solution by black gram husk (Cicer arientinum). Water Res., 37, 3472-3480 (2003).

Saeed, A., M. Iqbal and M.W. Akhtar: Removal and recovery of heavy metals from aqueous solution using papaya wood as a new biosorbent. Sep. Purif. Technol., 45, 25-31(2005).

Sawalha, M.F., J.R.P. Videa, J.R. Gonza'lez and J.L.G. Torresdey,: Biosorption of $\mathrm{Cd}(\mathrm{II}), \mathrm{Cr}(\mathrm{III})$, and $\mathrm{Cr}(\mathrm{VI})$ by saltbush (Atriplex canescens) biomass: Thermodynamic and isotherm studies. J Colloid Inter. Sci., 300, 100-104 (2007).

Sawalha, M.F., J.R.P. Videa, J.R. Gonza'lez, M.D. Gardea and J.L.G. Torresdey: Thermodynamic and isotherm studies of the biosorption of $\mathrm{Cu}(\mathrm{II}), \mathrm{Pb}(\mathrm{II})$, and $\mathrm{Zn}(\mathrm{II})$ by leaves of saltbush (Atriplex canescens). J. Chem. Thermodyn., 39, 488-492 (2007).

Selatnia, A., N. Boukazoula, N. Kechid, M.Z. Bakhti, A. Chergui and Y. Kerchich: Biosorption of lead (II) from aqueous solution by a bacterial dead Streptomyces rimosus biomass. Biochem. Eng. J., 19, 127-135(2004).

Villaescusa, I., N. Fiol, N. Martínez, N. Miralles and J. Poch: Removal of copper and nickel ions from aqueous solutions by grape stalks wastes. Water Res., 38, 992-1002 (2004).

Wachter, R. and A. Cordery: Response surface methodology modelling of diamond like carbon film deposition. Carbon, 37, 1529-1537 (1999).

Yih-Fong, T. and F.C. Chen: Multi-objective process optimization for turning of tool steel. Int. J. Mach. Machina. Mater., 1, 76-93 (2006).

Zulkali, M.M.D., A.L. Ahmad and N.H. Norulakmal: Oryza sativa L. husk as heavy metal adsorbent: Optimization with lead as model solution. Bioresour. Technol., 97, 21-25(2006). 